when approached by another group, when traversing unfamiliar terrain or when in heavy undergrowth. In open familiar terrain individuals often become much dispersed. In view of the often grossly exaggerated popular accounts of the significance of animal territory for human behaviour it is worth stressing that the Altmanns' baboons showed "no convincing evidence for territoriality, in the sense of a defended area". 'This seems to be true generally for open country primates most similar in many behavioural respects to man.

The Altmanns noted that their baboons prey on insects, worms, reptiles, birds' eggs and chicks, harcs, a fossorial rodent, a young Grant's gazelle, vervet monkeys and bushbabics. True hunting and chasing were recorded, particularly from certain individuals who appeared to be adepts. After the capture of meat there were often agonistic encounters over its possession which were settled apparently according to the social status of the disputants. Rarely do baboon watchers observe actual attacks by predators on their animals nor the defensive behaviour that may sometimes be shown. The Altmanns recorded cases in which males and sometimes also females lunged at or chased a predator, and they also observed a new response to the appearance of a predator--crouching cryptically and motionlessly in the grass. The records of a degree of cooperative defence are important for their occurrence has sometimes been denied. Such events have also been seen in the Patas monkey in a comparable African habitat.

This study confirms the impression that baboon social life is rich and that the relation between social dynamies, population dynamics and ecology comprise for these animals a complex system that will require long-term quantitative investigations of known marked populations over several years, supplemented by experiments on separate test populations. Until primate ecology reaches the standard of comparable work with birds much will remain mysterious. But monkeys are not birds and we can glimpse already the elements of the socioecological system which, on a parallel track, was to lead eventually to man.

This study is essential reading for primatologists, social ethologists and anthropologists and can be read with profit at any stage of an individual career.

JoHN H. CRook

\section{CHIMPANZEE TOPICS}

\section{Physiology, Behavior, Serology, and Diseases of Chimpanzees}

Editod by G. H. Bourne. (The Chimpanzee, Vol. 2.) Pp. $x+417$. (Karger: Basel and New York, 1970.) 115 franes; $230 s$.

The chimpanzee has, for long, attracted scientific attention, principally because of the well documented view that, along with the gorilla and orang-utan, it is structurally and functionally most closely related to man. Morphological study of the chimpanzee dates from Tyson's publication in 1699 of the Anatomy of a Pygmie, but the foundation, on an appreciable scale, of pioneering studies of the physiology and behaviour of this genus, dates only from the $1930 \mathrm{~s}$. Because the animal is relatively big and presents other difficulties in its husbandry, research into chimpanzee physiology and behaviour is still limited although, in common with work on other primate groups, its study has received impetus during the past decade following the establishment in the United States of America of centres for primate research, and with the elaboration of the space research programmes.

This volume is the second of a planned series designed to form ultimately "a comprehensive study of this species". As a matter of editorial policy, subjects are dispersed, each volume having "a selection of chapters dealing with a variety of aspects of the study of the chimpanzee". The result is that this volume, like its predecessor, covers a big and seemingly disconnected variety of topics ranging from studies in visual physiology, through analyses of renal function, energy metabolism and body temperature, to an examination of the chimpanzee's taste modality. Morphological studies comprise a significant section of the work and include a formal description of the spinal cord of the chimpanzee. This is followed by an exemplary analysis of the limbs, carried out in the now established tradition of inquiring quantitatively into correlations between, on the one hand, form and structure and, on the other, locomotor and other functional uses.

The chromosomes of the animal are next considered and this study is followed by chapters dealing with social and other types of chimpanzee behaviour. The now well known modern work on chimpanzee serology is summarized, and the volume concludes with two chapters aimed towards an advancement of the husbandry of the spocies, and dealing first with the viruses pathogenic to chimpanzees and second with the isolation of mycoplasmas.

Comparison with other primate genera even those for which reasonable amounts of information are availableis, of necessity, limited. Nevertheless, comparison with man and sometimes with the other apes understandablypermeates most contributions, and here two contrasting groups of findings omerge. In some fields, for example adaptation in the limbs, the chimpanzee is very different from man. In many other fiolds-including some as. fundamental as studies of the chromosomes - there is, in spite of some contrasts, a great similarity between this ape and man. In the case of the "genetically informative macromolecules" the similarity is such as to depict (in this one feature) "a closer genealogical relationship of the African apes to man than to the Asiatic apes".

The synthesis of such contrasting information to provide a basis for assessing evolutionary relationships is a problem now developing in both concept and methodology". Its solution could well be the responsibility of a future generation.

E. H. Ashton

\section{ATLAS OF AFRICAN BIRDS}

An Atlas of Speciation in African Passerine Birds

By B. P. Hall and R. E. Moreau. Pp. xv + 423 (439 maps). (British Museum (Natural History): London, 1970.) $300 s$.

To quote the foreword by Professor Ernst Mayr, this is "a superb achievement". It roprosents the gigantic task of plotting, for 962 species, the localities recorded in the extensive literature and in data of principal museum collections. The information is very clearly presented by symbols on a series of identical maps; further, it is arranged in a meaningful way, so that the atlas is verr much more than an assembly of study material. The theme is the superspecies, or in some cases the wider species group, and all the species belonging to any one such eategory are shown together on a single map. The grouping of species in this way is of course a matter of taxonomic judgment, but the authors' reasons are duly given in the text. Of the total, 176 species are ranked as standing alone and are separately mapped.

Each map, with its explanatory text, occupies a page; and, where practicable, closely related groups are allotted facing pages. The species included are the members of the Passeriformes breeding in continental Africa south of $20^{\circ} \mathrm{N}$ latitude. (Non-passerine birds were found, in general, to require treatment on a world rather than a regional basis and have therefore been wisoly excluded from the scope of the work.) Species peculiar to Mada- 
gascar and other islands have been omitted, except in the small minority of instances where they represent superspecies of which other forms are truly African. In the case of superspecies of wide distribution, inset maps of the world are provided to show the extra-limital representatives. The production of the large volume is excellent.

Nothing of the kind on this scale has been done for birds before. The carlier studies of evolution and speciation, from those of Darwin and Wallace onwards, were made on island populations, for which boundaries were predetermined and tended to remain stable, so that the outcome of segregation was often diagrammatic in its clarity. In a continental area the situation is apt to be much more complicated; and secondary changes in the environment produce secondary effects in the distribution of the avifauna. Keast had lately shown, however, that similar methods of study could be applied to Australian birds; and Mrs Hall herself had done it for the francolins of Africa. Here she has given an exposition on a grand scale, and with most impressive results.

She received much help and advice from the late R. E. Moreau, whose own work had documented the history of climate and vegetation in Africa in their relevance to the avifauna. The contraction and expansion of vegetation zones fracture the originally continuous distribution of avian (and other) species, and the resulting segregations lead to fresh speciation. Later, further changes in the environment bring the isolates into secondary contact, and various patterns emerge. The study of these last offers rich scope for further research, particularly by the field worker. Here is a firm basis for it; and case after case pose an intriguing problem.

\section{A. LANDSBOROUGH Thomson}

\section{ENCOUNTERS WITH SHARKS}

\section{The Shark}

Splendid Savage of the Sea. By Jacques-Yves Cousteau and Philippe Cousteau. (The Undersea Discoveries of Jacques-Yves Cousteau.) Pp. 277. (124 photographs in colour.) (Cassell: London, October 1970.) $50 \mathrm{~s}$.

IN February 1967 the Calypso sailed from Monaco to collect material for a series of television films on the sea. This book is the first of a series of six commissioned by Cassell, each of which will deal with a particular aspect of the work undertaken on this voyage: coral reefs, shipwrecks, whales and archaeology are the subjects of the next four volumes.

Many people who have enjoyed Cousteau's films may want to know more about them. Cousteau's introduction makes the point that the films tell little of the technical and personal problems, difficulties, and triumphs involved: these books are to complete the picture. This book is not a scientific account of sharks and this can never have been the authors' intention: it is not set at a lower level but rather in a different direction. The two Cousteausfather and son-adopt a narrative style to highlight some of the expedition's encounters with sharks in the Red Sea and Indian Ocean and they do it rather well. I was impressed by a simple account of a submarine dive near Socotra (pp. 181-8); and there can be few readers who will not be astounded by the description and photographs of the whale sharks. Not unexpectedly, much of the book is centred on or returns to the shark as a predator: there is a lot of biting and a lot of blood. Equipment, ship and crew are described and figured. I noted, with envy, that the Calypso carried a first-class cook and a maitre d'hôtel!

The text is translated from the French and generally reads well. But here and there dates and places jump. There seems to be a confusing break in continuity on p. 180 . The principal part of the text is printed on glazed paper and the layout is pleasant. But the production standards are not maintained in the last 40 pages which are unglazed and include an adequate index and twenty-two line figures. In the figure section the pages are confusingly see-through and are not numbered. The colour photographs vary in quality and some show a surprising amount of red which may result from using artificial illumination of a spectral composition inappropriate to the depth of water. But as a whole the book is good value for money.

This book, and the others to follow, should interest a wide public and libraries may expect a waiting list for their copy. The biologist will find some interesting observations: attacks on sharks by porpoises; evidence for territoriality in reef sharks; and the presence and behaviour of mice, hawks, and hermit crabs on the island of Derraka. But after reading the book I had the unhappy feeling of having bcen cheated: so much spectacle, so little measured. For example, the Cousteaus must have hundreds of metres of film on the movements of sharks. But has there been any attempt to relate fish length and swimming speed to tail-beat frequency? What I really want is another sort of book. Calypso sailed from Monaco, a town which I associate, not with the Grand Prix, but with Prince Albert's Résultats des Campagnes Scientifique accomplis sur son Yacht. May we yet look forward to a similar series, albeit less munificent, from Cousteau and his Calypso?

F. R. Harden Jones

\section{A PARLIAMENT OF OWLS}

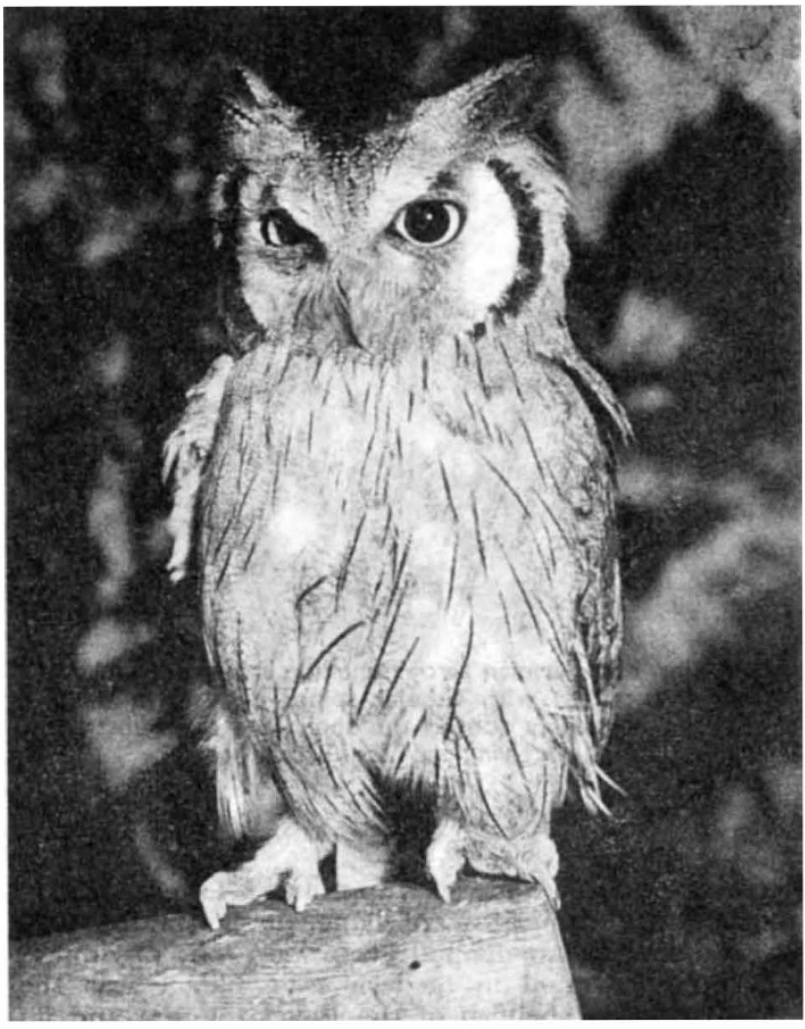

A white faced scops owl (Otus leucotis), one of more than 130 species of owl, some very rare, which are to be found around the world. The natural history of these curious birds of prey is told effectively by John Sparks and Tony Soper in Ow/s (David and Charles: Newton Abbot, October 1970, 50s), a book which should appeal to the naturalist and the general reader alike. 